\title{
In response to: "Radial Artery Cannulation at the Anatomical Snuffbox: Hype or Hope in Interventional Cardiology?"
}

\author{
Elton Soydan®, Mustafa Akın®
}

Department of Cardiology, Ege University School of Medicine, İzmir, Turkey

To the Editor,

We are very pleased to receive such an interesting paper in relation with our study "Left distal radial artery access site in primary percutaneous coronary intervention: Is it safe?"1 As the authors stated, distal radial artery cannulation at the anatomical snuffbox has become a popular alternative approach for coronary angiography and/or intervention in recent years. Due to the multiple anatomical and physiological mechanisms thoroughly described in our previous study, the left distal radial artery has been an innovative and potential approach for our patients since $2017 .^{2}$

We feel privileged to respond to the authors' few comments about this novel site in the clinical setting:

1. They are absolutely right about the impossibility of drawing firm conclusions of the safety of this access in female patients due to the possibility of a lower vascular caliber and fragile tissue characteristics. The relevant reference that the authors have related these features to was a study done by Naito T et al., where the caliber of the distal radial artery was found as $2.02 \pm 0.44 \mathrm{~mm} .{ }^{3}$ Interestingly, another study implemented by Norimatsu et al. showed that the caliber of the distal radial branch was $2.6 \pm 0.5 \mathrm{~mm}$, higher than the aforementioned study, thus implying variability in its caliber. ${ }^{4}$ Of note, these studies, done in Japan, have mostly used the right distal radial artery for caliber measurement - a feature that could be greatly differentiated from the relevant left side distal branch. In addition, difference in ethnicity could be another factor necessitating non-generalizability of the caliber of the distal radial artery at the anatomical snuffbox. Relating to this gap in information for the Turkish population, we completed a prospective study, already under review for publication, demonstrating that the caliber of the left distal radial artery at the anatomical snuffbox is $2.21 \pm 0.38 \mathrm{~mm}$, implying compatibility with a six French radial sheath. Higher rates of complications can be seen in the conventional radial approach, due to the deeper location of the main radial artery, being an area not restricted, and where bleeding or hematoma can be easily enlarged. In contrast, as we have stated in our study, the compact and restricted triangular area of the left distal radial branch could not pose as many complications as in the conventional radial area, due to its restricted anatomical structure and so being more protective against radial occlusion. ${ }^{1}$ Another important finding is its preservation of endothelial function, in comparison with the conventional radial artery. This is one of the mechanisms of vascular protection that was found in our recently published study. ${ }^{5}$ The conclusion of our study was only in relation with the results of this retrospective representative study, and not in generalizing the idea. It was further stated that "randomized controlled trials in comparison with other (conventional radial and/or femoral) access sites will accurately show its deserved place in the acute management of ST segment elevation myocardial infarction (STEMI) patients."

2. We do agree with the implementation of ultrasonography (USG) as an additional supporting tool to firstly assess the caliber of the distal radial branch for appropriate selection of the radial sheath. However, in the acute clinical setting of STEMI, it was not possible, and we were encouraged by the fact of the experience of at least 2 years, having performed 500 elective diagnostic and interventional coronary procedures. Indeed, the authors' estimation is of great importance and we totally agree again with the idea of incorporating USG measurement of the distal radial branch, especially in female patients and those with lower arm circumference.

3. Operator experience is of paramount importance in order to prevent any vascular complication during distal radial catheterization. As we mentioned above, we had a high experience that could be acceptable for use in primary percutaneous coronary intervention, the main feature accounting for a successful procedure with no vascular complications. However, because of the small size and the retrospective design of the

\footnotetext{
Address for Correspondence: Elton Soydan, Department of Cardiology, Ege University School of Medicine, İzmir, Turkey

e-mail: eltonsoydan@hotmail.com

DOI: 10.5152/balkanmedj.2021.21252

Available at www.balkanmedicaljournal.org

ORCID iDs of the authors: E.S. 0000-0002-9897-5484; M.A. 0000-0002-1850-9118.
}

Cite this article as:

Soydan E, Akın M. In response to: "Radial artery cannulation at the anatomical snuffbox: Hype or hope in interventional cardiology?". Balkan Med J. 2021 2021;38(4):253-254.

Copyright@Author(s)-Available online at http://balkanmedicaljournal.org/ 
study, we should be cautious about firm conclusions, thus necessitating prospective multicenter randomized controlled trials to better show its deserved place in the acute setting of STEMI. Regarding local anesthesia, different from the conventional radial cannulation, we have previously experienced loss of pulse of the distal radial branch at the anatomical snuffbox area after administering it before artery puncture. The possible mechanism of this feature was thought to be linked to the restricted area surrounded by bony structures, making the injection act as a mass to the relevant branch and decrease its pulsation feature. That is why we first punctured the artery with a 21 gauge open needle and then injected the local anesthesia, and lastly introduced the radial sheath: an issue that did not bother the patients.

Multiple studies have shown this novel radial approach to be protective, in comparison with the conventional one. Thus, as the authors described, radial artery cannulation at the anatomical snuffbox is a promising strategy in diagnostic and interventional coronary procedures. Indeed, these results should encourage us for the sake of desire for innovation in interventional cardiology. Increasing experience, combined with transparent perseverance as well, will certainly make us hopeful, with no doubts toward new approaches such as distal radial artery access and the possibility of reaching firm conclusions in the future.

Finally, we want to express our sincere appreciation for this scientific, high-quality letter on the distal radial artery.

Conflict of Interest: The authors have no conflicts of interest to declare.

\section{REFERENCES}

1. Soydan E, Akın M. Left distal radial artery access site in primary percutaneous coronary intervention: is it safe? Balkan Med J. 2020;37(5):276-280. [CrossRef].

2. Soydan E, Akın M. Coronary angiography using the left distal radial approach - an alternative site to conventional radial coronary angiography. Anatol J Cardiol. 2018;19(4):243-248. [CrossRef].

3. Naito T, Sawaoka T, Sasaki K, et al. Evaluation of the diameter of the distal radial artery at the anatomical snuff box using ultrasound in Japanese patients. Cardiovasc Interv Ther. 2019;34(4):312-316. [CrossRef].

4. Norimatsu K, Kusumoto T, Yoshimoto K, et al. Importance of measurement of the diameter of the distal radial artery in a distal radial approach from the anatomical snuffbox before coronary catheterization. Heart Vessels. 2019;34(10):1615-1620. [CrossRef].

5. Soydan E, Kış M, Akın M. Evaluation of radial artery endothelial functions in transradial coronary angiography according to different radial access sites. Anatol J Cardiol. 2021;25(1):42-48. [CrossRef]. 